\title{
Spatial energy predictions from large-scale photovoltaic power plants located in optimal sites and connected to a smart grid in Peninsular Malaysia
}

\begin{abstract}
In order to make accurate energy predictions for large-scale photovoltaic (PV) systems connected to a smart grid, it is first necessary to identify the very specific locations that are required for their long-term optimal operation. Multi-criteria evaluation techniques are often applied for different site selection studies. This study discusses the past, present and future condition of solar PV application in Malaysia. The study also uses the optimal site definition model (ODM) and GIS to select sites for the installation of large-scale PV power plants that will be connected to a smart grid, and to predict their technical potential and carbon emission reduction, based on optimal sites in Peninsular Malaysia. The outcome of the study reveals that policies and strategies being adopted by Malaysia government are significantly improving the solar PV application for energy sustainability. However, on the other aspect, the results show that $10,092.08 \mathrm{~km}^{2}(7.64 \%)$ of the area under study is suitable for large-scale PV plant installation. If even half of the potential sites are used, with an installed capacity of $756.91 \mathrm{GW}$, we predict a total electricity generation potential of 1,343,527.9 GWh/yr with an annual carbon emission reduction of $846,422.56 \mathrm{kt}-\mathrm{CO}_{2} / \mathrm{yr}$ in Peninsular Malaysia. Based on predicted national energy consumption in 2030, this study shows that about 8 times future annual energy consumption could be met if PV plants with an installed capacity of 756.91 GW are set up in Peninsular Malaysia. Similarly, the study predicts an improvement of 1.6 times the annual carbon emission reduction, based on predicted carbon emissions for 2020. Therefore, the implementation of large-scale PV applications is technically and environmentally viable in Peninsular Malaysia and tropical countries as a whole.
\end{abstract}

Keyword: Geographic information systems (GIS); Photovoltaic power (PV) plants; Optimal sites; Carbon emission reduction; Energy generation; Installation capacity 